\title{
Efficient motivation for studying crocodilian learning
}

JOHN T. WILLIAMS, JR.

VA HOSPITAL, AUGUSTA, GEORGIA

It was found that escape from electric shock is quite effective as a means of motivating crocodilians in a learning situation. However, the Ss should be run when wet to prevent drastic increases in resistance as the Ss dry out. Also, an 18 in. caiman requires a much higher shock intensity than a rat for comparable results.

One of the obstacles which a comparative psychologist must overcome is the problem of learning how to maintain and motivate animals which are not usually used as experimental Ss. Davidson (1966) has recently published some reversal learning results using alligators as Ss. He used heat escape for motivation and a water tank for a goal box. The aversiveness of the heat lamps was reduced whenever the Ss were wet, so the Ss were kept on water deprivation and run only four trials per week. Of his eight Ss, one died, seven learned one reversal, and only three were taught a second reversal. Obviously, if one is interested in following the course of learning across a series of reversals (or on any other task in which a substantial number of trials are necessary to give meaningful results), some more efficient source of motivation is necessary. Also, as Davidson pointed out, food deprivation is ineffective, since crocodilians can withstand starvation for long periods of time.

Shock escape seemed to be a logical source of motivation, since shock intensity is easily manipulated to suit the sensitivity of the Ss. Early pilot work confirmed the observations of others that crocodilians (in this case Caiman sclerops) adapt to shock very quickly, but it was found that they did not adapt when immersed in water before each trial. Thus, it was an increase in electrical resistance as the $S$ dried out that caused the apparent adaptation to shock. Rather than adaptation, there was a cumulative effect of shock if the intertrial interval was very short. A $10 \mathrm{~min}$ intertrial interval was found to be sufficient to prevent the motor impairment which resulted from highly massed trials. This pilot work regarding reactions to shock was done with a grid designed for use with rats, and the caimans (about 18 in. long) would frequently get a leg caught between two grid bars. Since defecation only occurred about once a week and was never observed as an emotional reaction to shock, it was possible to build a grid without worrying that defecation might short circuit grid bars. Stainless steel plates 1 in. wide, separated by $1 / 8$ in. spaces, were used for the floor of a $T$ maze with galvanized metal sides which were wired to prevent climbing. Removable metal pans, containing water from the home tank, served as goal boxes. To avoid handling Ss in the goal area, the Ss were carried to their home tank in the goal pans and allowed to swim out into the tank. Observations were made by using a mirror mounted at an angle over the maze.

A variable voltage transformer was used to deliver shock through a shock scrambler so that it was impossible for the Ss to escape shock by standing on certain grid plates. At first it appeared that this apparatus was perfectly suited for the studies which were to be conducted, but it soon became apparent that the commercially bullt scrambler was unable to carry the currents (6 to 8 milliamps short circuit at the grid) necessary for adequate motivation over a prolonged period of sustained operation. To remedy this situation, a scrambler was built using relays with contacts rated at 10 amps. Eight 3PDT relays were used to build a scrambler with 16 outlet wires to the grid. One switch of each relay was used to produce a self-cycling ring in which the first relay closed the second which closed the third, etc. When the last relay closed, this opened the first relay which opened the second, etc. The other two switches on each relay were used to distribute the shock from the shock source to the grid. This proved to be a highly reliable scrambler, as well as being relatively inexpensive. (More complete details and a diagram for either an eight or 16 outlet scrambler are available from the author.)

It has been possible to run Ss the desired 20 trials per day, seven days per week, with no motivational problems, and only a very small number of Ss have been discarded because of abnormal reactions to shock.

\section{Reference}

Davidson, R. S., Jr. Laboratory maintenance and learning of Alligator mississippiensis. Psychol. Rep., 1966, 19, 595-601. 